\title{
2006-2631: PRACTICAL DESIGN OF WHARF EXTENSION IN SOUTH
}

\section{CAROLINA}

\section{Robert Dullanty, ATM}

Mr. Dullanty is a Principal at Applied Technology \& Management, Inc. in Charleston, SC. A graduate of the University of Washington, Mr. Dullanty specializes in Marine Structures and is comfortable in environments as diverse as the Alaskan Tundra to the balmy climate of South Carolina, Florida and the Caribbean. After leaving the South Carolina State Ports Authority, Mr. Dullanty started his own engineering firm and in the summer of 2005 joined forces Applied Technology \& Management, Inc. 


\title{
2006-2631: Practical Design of Wharf Extension in South Carolina
}

\begin{abstract}
Criterion 3 of ABET 2004-2005 Criteria for Accrediting Engineering Programs requires that all engineering programs seeking accreditation manifest that their graduates have an ability to "function on multidisciplinary teams." Students should be able to serve as both a team leader and a contributing member of a design team. This paper presents a case study of one heavy marine structure in the Georgetown, South Carolina. Heavy marine structures typically involve large and unusual loads from cranes, ships, and cargo; generally are supported upon weak and sloped soils; and usually require significant design considerations for marine and coastal environments including corrosive conditions. Marine structures provide for excellent classroom case studies because they inherently require multidisciplinary evaluation and site specific engineering solutions.
\end{abstract}

Introduction

This paper discusses practical design considerations for a heavy marine structure in South Carolina. As an example, it uses one project from the South Carolina State Ports Authority. The project is the extension of a commercial break bulk cargo wharf at the Georgetown Terminal in Georgetown, SC,

The South Carolina State Ports Authority (Ports Authority) operates six waterfront sites that handle containerized cargo, bulk cargo and break-bulk cargo. As a container port, Charleston generally ranks fourth in the U.S. in terms of containerized cargo volume. This is done through four terminal sites located in the Charleston, South Carolina area. The South Carolina State Ports Authority also operates two smaller bulk and break-bulk ports located in Port Royal, South Carolina and Georgetown, South Carolina.

Wharf Extension of the Georgetown Terminal

The Georgetown Terminal is a dedicated breakbulk and bulk cargo facility. The top commodities are steel, salt, cement, aggregates and forest products. Pier $31 \mathrm{C}$ at the Georgetown Terminal is a 500 -foot wharf. Ships calling on this facility were routinely exceeding this 500 foot length and often required moving the ship to allow full access for unloading and loading cargo. These multiple ship moves increased the cost of unloading due to additional tug assist time during the multiple moves and additional time in-port to unload. To accommodate these larger ship sizes, the Ports Authority desired to extend the existing wharf from 500-feet to 600feet. 
The existing wharf structure was a concrete slab area, approximately 500 -feet by 200 -feet, supported upon prestressed concrete piles. The slab was both the foundation for a warehouse structure as well as the wharf area. The useable wharf area outside the building structure was approximately 40 -foot in width and 500-feet long. The prestressed concrete piles supporting the slab had steel h-pile points driven a few feet into the limestone below. These piles did not resist uplift forces. Uplift forces from lateral loads were resisted by the wide geometry and self-weight of the existing slab and warehouse.

The soils below the wharf area consisted of soft river deposits overlaying interbedded limestone and silt layers of the Pee Dee Formation. Typical standard penetration test $\mathrm{N}$ values in the limestone were 50 blows per 6-inches. Previous experience with installing piles through this layer has shown that typical pres-stressed, pre-cast concrete piles can experience practical refusal or damage during pile installation.

The Ports Authority desired to expand the wharf length by 100 -feet long, but chose to restrict the width of this extension to 40 -feet. To resist the lateral forces upon this narrow extension, pile penetration into the limestone layer was required. Open-ended pile piles with thick walls were selected for their high strength and small bearing area to allow the piles to be driven into the limestone. A batter pile system was chosen for the construction of this extension, requiring uplift resistance for some of these piles.

The wharf extension was designed for a variety of conditions that included mooring and breasting forces from the ships, crane and truck forces upon the wharf, a $600 \mathrm{psf}$ uniform load for cargo, seismic forces, water forces, and resistance to corrosion in a salt water environment. The structural design was performed in accordance with AASHTO specifications for bridge design, ACI specifications for concrete design, AISC specifications for steel design, and industry standards for ship impact and mooring forces. The concrete used on the project included a 28day compressive strength of 5,000 psi and incorporated a corrosion inhibiter additive. Concrete was manufactured, placed and cured under various specifications and standards including ACI 301, ACI 304, ACI 305 and ASTM C94.

Installation of the pipe piles into the limestone was a concern and several parameters and procedures were selected to ensure a successful design. The design required a steel pipe diameter of 20 -inches and a wall thickness of $1 / 2$ inch, construction planning included a WEAP analysis to properly size the hammer and other installation parameters, and dynamic testing of the piles after installation was performed to verify their capacity. The result was the successful installation of steel pipe piles with capacities verified with the dynamic testing.

The concrete superstructure was installed during the summer months in South Carolina and required proper precautions for Hot Weather Concreting as provided for in ACI 305. Although some difficulties were encountered with the placement of the concrete, these difficulties were attributed to failing to properly conform to the ACI 305 Hot Weather Concreting requirements. The difficulties and any resulting deficiencies were corrected by the General Contractor without any encumbrance to the Ports Authority. 
The Ports Authority's Georgetown Terminal continues to operate as a break bulk facility with increased efficiency for the longer ships calling upon their wharf. In addition to this wharf extension for cargo unloading, improved mooring capacity have been added to the facility through the use of pipe-pile mooring and breasting dolphins. These pipe piles for the mooring dolphins also penetrate the limestone layer and resist uplift forces. Photos of the wharf extension and these mooring and breasting dolphins are presented below.

In summary, marine structures present an excellent opportunity to work with multiple engineering disciplines. They also allow for the use of multiple codes and references such as the AASHTO Bridge Code, UBC Building Codes, and areas where these traditional codes do not apply such as mooring loads and fender analysis.

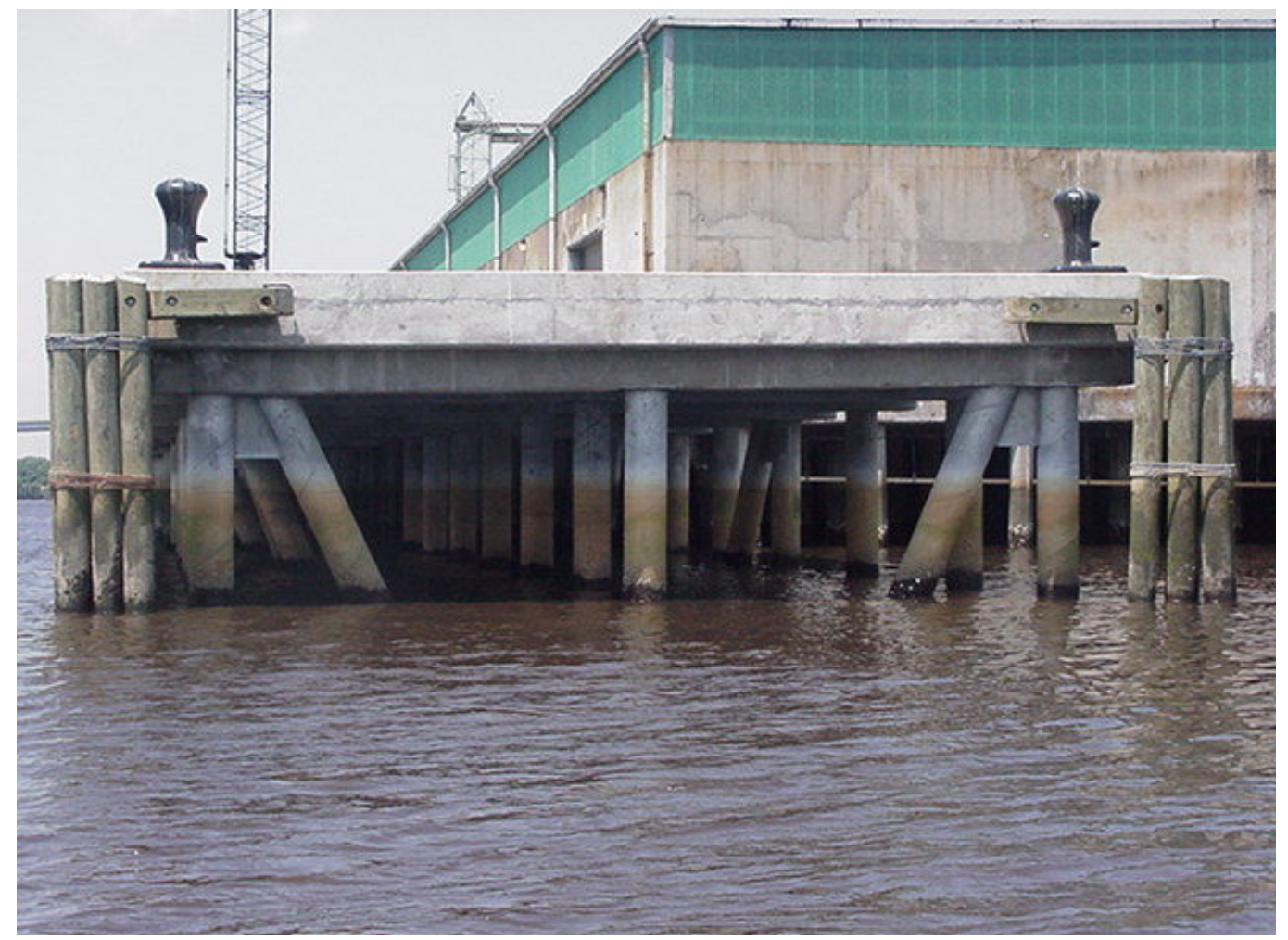

Photograph 1: Wharf Extension in Georgetown, South Carolina. This shows the vertical and batter steel pipe piles below the wharf extension. 


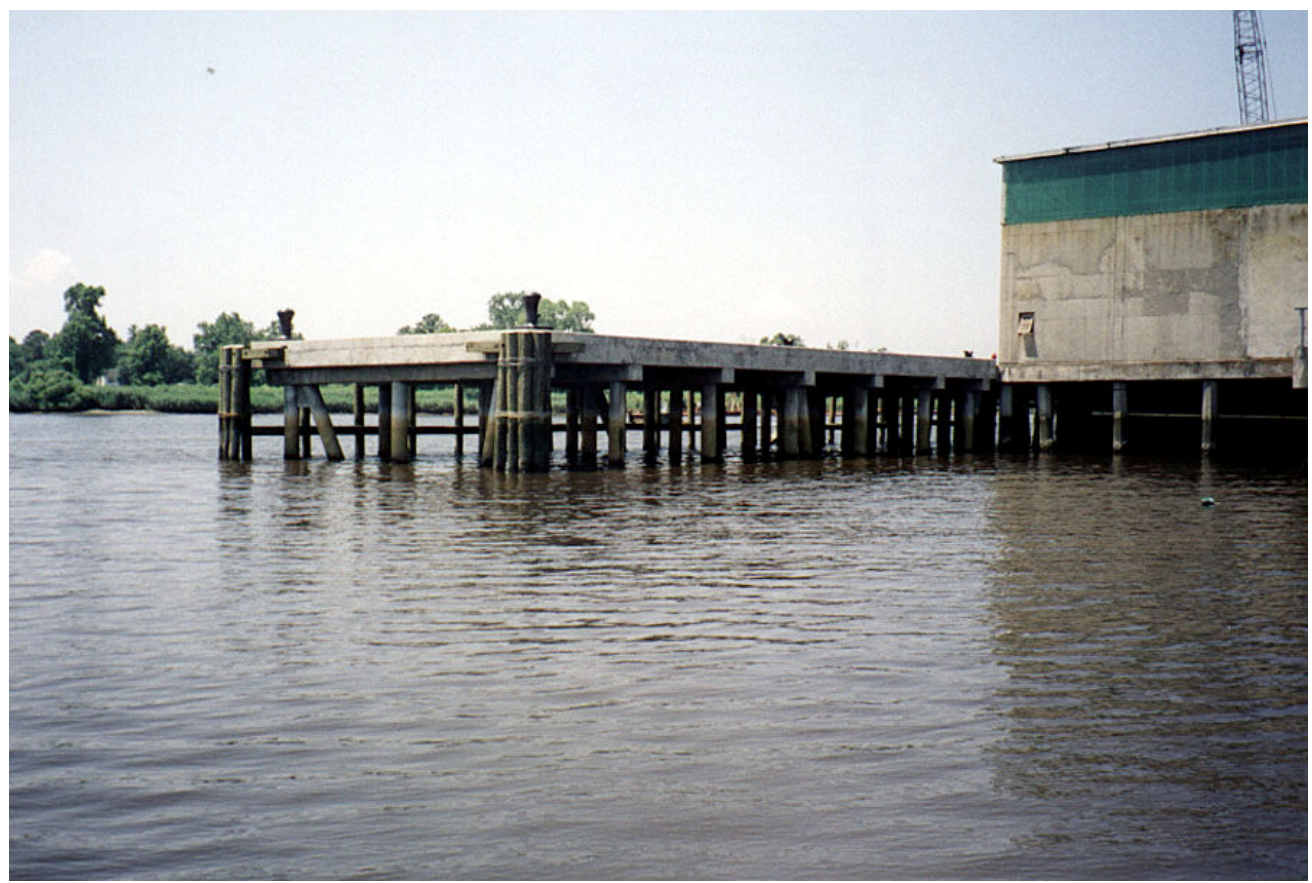

Photograph 2: Wharf Extension in Georgetown, South Carolina.

This project required an evaluation of ship impact forces, seismic forces, heavy vertical loads from cargo and cargo transfer equipment, and protection of the materials from the corrosive effects of salt water.

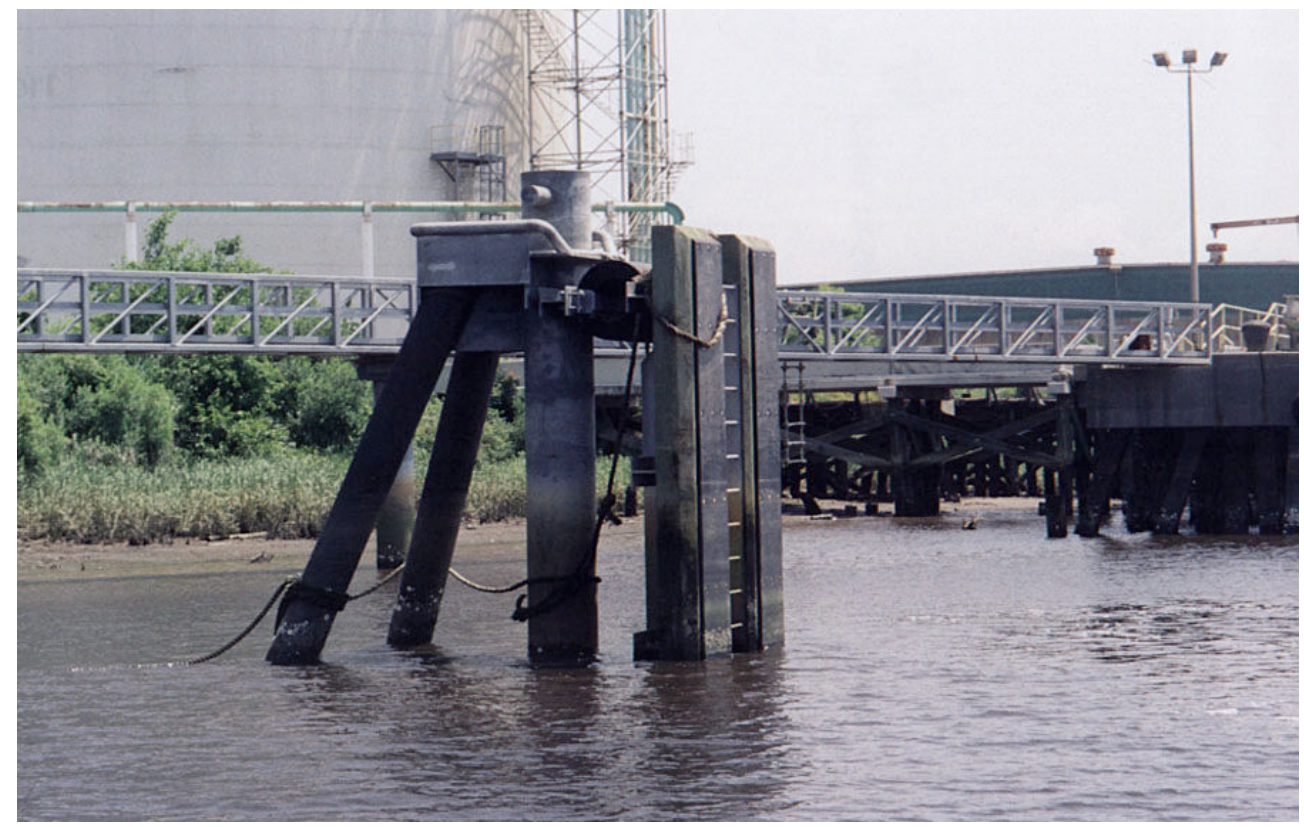

Photograph 3: Breasting and Mooring Dolphin in Georgetown, South Carolina. This project required an energy evaluation of ship impact forces to determine the design forces, and the design of the structure to transfer 50-tons of horizontal force into soils consisting of limestone over silt. 


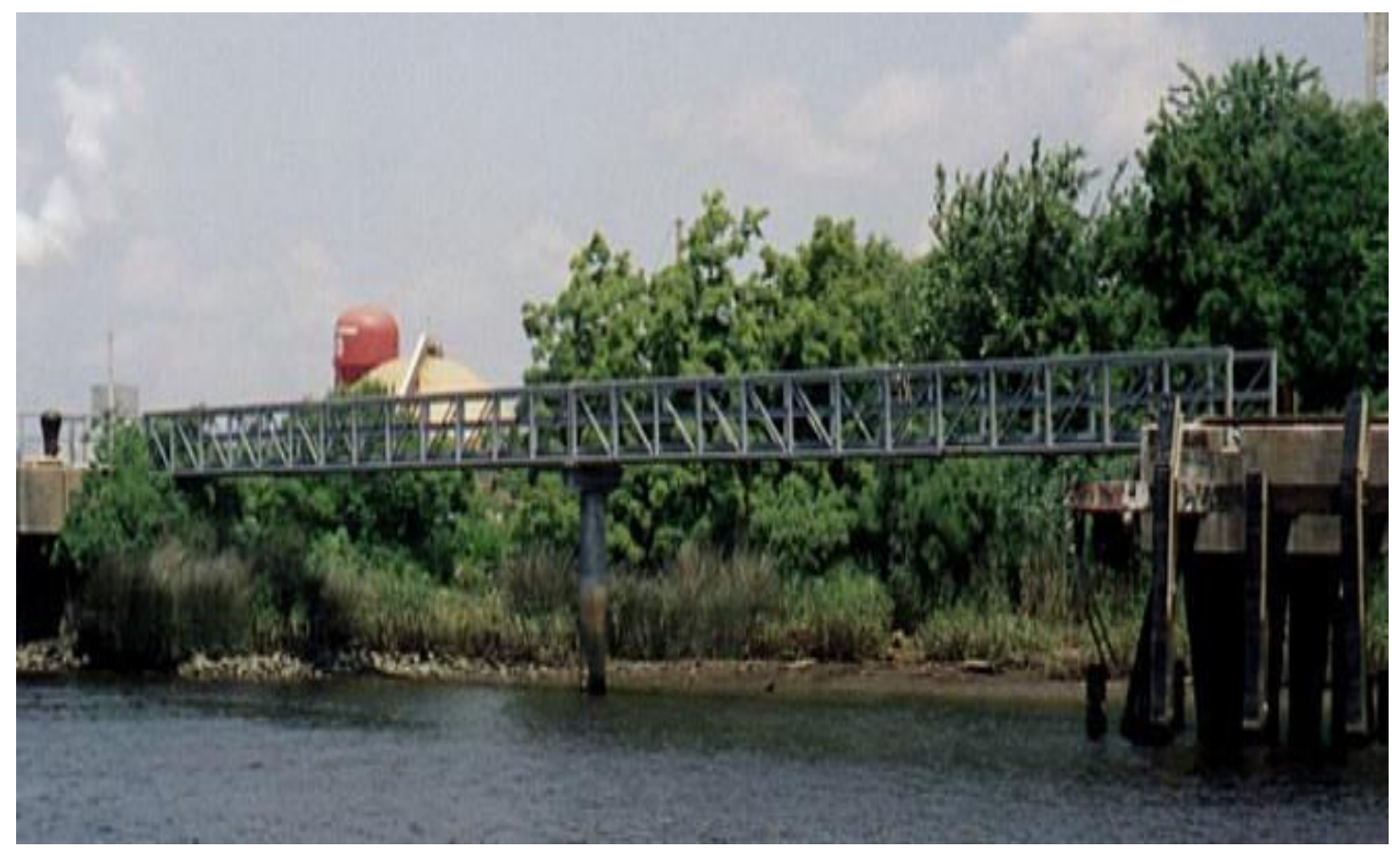

Photograph 4: Catwalk to Mooring Dolphin in Georgetown, South Carolina.

This project required evaluation of a simple long span truss structure over the difficult soil conditions of shallow weak soils overlaying limestone.

\section{References}

1. ABET, ABET 2004-2005 Criteria for Accrediting Engineering Programs, Accreditation Board for Engineering and Technology, Baltimore, MD. 